\title{
О БРОКЕРЕ «БЕДНОМ ЗАМОЛВИТЕ СЛОВО»: ОБЗОР ПРАКТИКИ ПРИМЕНЕНИЯ ПУНКТА 4 СТАТЬИ 405 ТАМОЖЕННОГО КОДЕКСА ЕАЭС
}

\author{
(C) 2021 Матвиенко Галина Владимировна
}

кандидат юридических наук, доцент, профессор кафедры финансового права Российский государственный университет правосудия (РГУП), Россия, Москва E-mail: galina7772005@yandex.ru

Применение норм таможенного законодательства о солидарной обязанности таможенного представителя уплачивать таможенные платежи раскрывается в контексте современной правоприменительной практики, складывающейся под влиянием органов правосудия России и Суда Евразийского экономического союза. Традиционная позиция, сложившаяся в науке, подтверждается тенденциями судебной практики: в силу публичного характера правоотношений в области таможенного обложения, солидарная обязанность погасить таможенный долг имеет преимущественное значение перед договорными обязательствами таможенного представителя (брокера) и декларанта. Это, однако, не исключает возможности взыскать уплаченные средства с декларанта в регрессном порядке. Решение этого вопроса находится за пределами действия норм таможенного права и зависит от объема договорных обязательств таможенного представителя и добросовестности их исполнения. В статье также затронуты проблемы реализации принципов стабильности таможенноправовых норм и недопустимости придания обратной силы закону, несоблюдение которых нередко ведет к нарушению баланса частных и публичных интересов, ставит под угрозу существование института таможенных представителей. В заключительной части настоящего исследования приведены предложения законодателю и органам ЕАЭС, нацеленные на совершенствование контроля за деятельностью названной категории посредников в таможенном деле и профилактику споров с их участием.

Ключевые слова: Суд ЕАЭС, таможенный представитель (таможенный брокер), декларант, солидарная обязанность уплатить таможенные платежи, таможенный долг, регресс, классификация товаров в таможенных целях, таможенные споры.

Соотношение солидарной обязанности платить таможенные пошлины и налоги и договорных обязательств таможенного представителя неоднократно становились предметом научных дискуссий, а также судебных разбирательств. Импульсом для настоящего исследования послужило дело, окончательное решение по которому приняла Апелляционная палата Суда Евразийского экономического союза летом 2021 года [24].

Краткая фабула дела такова. Таможенный представитель - ООО «ДХЛ Глобал Форврадинг» не обеспечил надлежащего исполнения обязательства по достоверному декларированию товара, ввиду чего по итогам камеральной проверки таможня изменила его классификацию в соответствии с Единой товарной номенклатурой внешнеэкономической деятельности и потребовала уплатить около тридцати миллионов рублей. Декларант с притязаниями таможни не согласился, заключил с брокером дополнительное соглашение, на основании которого последний возлагал на себя обязательство представлять интересы поручителя в деле об оспаривании решений таможни. Арбитражный суд приостановил исполнение требования фиска до момента разрешения спора, однако брокер, к тому моменту исключенный из реестра по причине совершенных правонарушений, не связанных с рассматриваемым делом, полностью возместил недоимку по таможенным платежам, невзирая на возражения декларанта. В итоге последний отказался компенсировать эти затраты. Суды пришли к выводу, что в таком случае для брокера неизбежны последствия действия в чужом интересе без поручения, предусмотренные статьями 983, 984 Гражданского кодекса РФ. Спорные расходы представителя, как указано в одном из решений по делу, «образовались вследствие неправильной классификации им товаров, поэтому такие расходы в силу статей 15 , 393 Гражданского кодекса Российской Федерации являются его ответственностью за ненадлежащее исполнение договора» [7]. 
Таможенный представитель обратился в Евразийскую экономическую комиссию с просьбой обеспечить соблюдение в России норм таможенного права Союза о солидарной обязанности по уплате таможенных платежей, возникающей у таможенного представителя и декларанта. По мнению истца, состоявшиеся по делу судебные акты фактически лишают его права на регрессное взыскание уплаченных во исполнение солидарной обязанности таможенных платежей, создают условия для уклонения от их уплаты недобросовестным декларантам, ставят под сомнение существование института таможенных представителей как гарантов исполнения публичных обязанностей.

Комиссия Союза отказала таможенному представителю в совершении ожидаемых действий, посчитав, что взаимные претензии брокера и декларанта лежат вне сферы регулирования права Союза, а, значит, и области деятельности Комиссии.

Представитель названного общества обратился в Суд ЕАЭС, пояснив также, что уплата таможенных платежей осуществляется таможенным брокером в силу публично-правовой обязанности и «их размер не может быть поставлен в зависимость от условий договора». Коллегия Суда ЕАЭС приняла сторону таможенного представителя.

Приведем здесь некоторые доводы Коллегии в пользу принятого решения:

- обращаясь в Комиссию, истец ожидал с ее стороны действий, направленных на устранение коллизий по применению права Союза в нормативных актах и в национальной практике по вопросу реализации солидарной обязанности указанных субъектов таможенных правоотношений;

- солидарная обязанность таможенного представителя и декларанта закреплена правом Союза - в международном договоре, т.е. являет собой «солидарную обязанность из закона»; в отличие от солидарной обязанности из гражданско-правового договора, возмещение уплатившему лицу в данном случае осуществляется полностью;

- национальное законодательство, равно как и содержание договора между брокером и декларантом, «не могут нивелировать этого института без последующей компенсации всей суммы уплаченных таможенных платежей»; при возникновении коллизии между правом Союза и национальным законодательством подлежит применению право Союза;

- Комиссия Союза не учла связи солидарной обязанности с нормой международного публичного права, указав, что отношения декларанта и брокера строятся на договорной основе, т.е. находятся за пределами ведения Комиссии, хотя договор не может регулировать ответственность указанных субъектов за неисполнение обязанностей по уплате таможенных платежей [26, пп. 5.3, 5.5].

Апелляционная инстанция отклонила все доводы Коллегии Суда ЕАЭС, отменила решение и поддержала Комиссию [24]. Полагаю, с этим решением нельзя не согласиться.

Во-первых, не ставится под сомнение тот факт, что правовой статус таможенного представителя как особой разновидности посредника [3, С. 371, 380-381; 5, С. 41-44] основан на нормах различной отраслевой принадлежности, реализация положений которых в комплексе и позволяет в конечном итоге оказать услуги декларанту по исполнению последним базовых публичноправовых обязанностей - подать декларацию и уплатить таможенные платежи. Основу правового регулирования отношений таможенного представителя, декларанта и таможни в области таможенного обложения составляют материальные и процедурные нормы публичного (прежде всего, таможенного) и гражданского права. На комплексный характер в регулировании деятельности рассматриваемого субъекта указывают практически все ученые, которые исследует различные аспекты его правового статуса [6, С. 11-112; 11, C. 111; 29, C. 13-14].

Деятельность рассматриваемого субъекта околотаможенной инфраструктуры, включенного в специальный реестр, заключается в оказании на профессиональной основе особой разновидности таможенных услуг, связанных с указанием по поручению декларанта полной, достоверной, документально подтвержденной информации в декларации на товар. Не случайно информация о таможенном представителе обязательно вносится в декларацию: таможне должно быть известно, кто конкретно несет ответственность за заявление сведений. Если декларацию, согласно договору, поручено подавать брокеру, классификационный код ТН ВЭД, таможенную стоимость и иные сведения о товаре указывает именно он. Так, часть 2 ст. 106 3акона о таможенном регулировании от 27 ноября 
2010 г. № 311-ФЗ устанавливала: «В таможенной декларации на товары код товара по Товарной номенклатуре внешнеэкономической деятельности указывается декларантом либо по поручению декларанта таможенным представителем». Аналогичное правило следует и из действующего отечественного Закона [27, ч. 1 ст. 15]. Особо отметим: прибыль брокер извлекает именно в результате деятельности, нацеленной на достоверное декларирование товара интересанта, в том числе осуществляемой в целях полной и своевременной уплаты таможенных платежей представляемым лицом.

Верно указывает Апелляционная палата Суда Союза: «публично-правовой характер солидарной обязанности возникает между таможенным представителем и государством-членом в связи с деятельностью» брокера от имени декларанта [1, п. 4 ст. 405] и «прекращается исполнением таможенного обязательства» [24, абз. 10 п. 5.4.]. В нормах таможенного права законодатель термином «обязательство» не оперирует. Представляется, однако, что, по существу, солидарная обязанность уплачивать таможенные платежи схожа с солидарным обязательством пассивного типа: «кредитор вправе требовать исполнения обязательств в полном объеме от любого из должников» [2, С. 71].

В этой связи законодателем особо подчеркивается: обязанности таможенного представителя перед таможенными органами не могут быть ограничены договором с представляемым лицом [1, п. 7 ст. 405]". Фактически, для фиска не имеет значение, как распределены между сторонами договорные обязательства, каков перечень услуг, оказываемых представителем. Главное, что таможенный долг гарантированно будет возмещен по первому требованию, если не декларантом, то брокером. Так обеспечивается удовлетворение интересов казны. Нормы таможенного законодательства имеют в таком контексте преимущественное значение перед договорными обязательствами, поскольку императивность в регулировании таможеннотарифных отношений сохраняется независимо от того, кто выступает в качестве обязанноголица, на что справедливо указывает А.Н.Козырин [3, С. 373-374]. И, если продолжить рассуждение в терминах цивилистики, т.н. таможенное обязательство возникает лишь по инициативе одной стороны - государства, и имеет односторонне- властный характер [4, С. 47]. Причем для фиска в этом случае таможенный представитель фактически выступает в качестве равновеликой декларанту стороны: несмотря на отсутствие полной аналогии в их статусе [28, С. 37], совокупность прав и обязанностей, ответственность перед таможенным органом позволяет определить брокера «в качестве декларанта в силу обязанности по договору» [6, С. 111].

Во-вторых, какая-либо коллизия между нормами ТК ЕАЭС и гражданским законодательством по вопросу солидарной обязанности, отсутствует. Поясню данный тезис.

Действующий в период развития спорных правоотношений Таможенный кодекс Таможенного союза, а сейчас и ТК ЕАЭС прямо признают договорный характер отношений таможенного представителя и декларанта, а, значит, не исключают право на регрессное взыскание с декларанта сумм, уплаченных таможенным представителем во исполнение солидарной обязанности по уплате таможенных платежей.

В Таможенном кодексе ЕАЭС имеется указание на то, что термины гражданского законодательства применяются в нем в том значении, которое подразумевает национальный законодатель [1, п. 6 ст. 2]. Верно отмечает судья Д.Г.Колос: поскольку государства-члены Союза не оговаривают применение термина «солидарная обязанность» в каком-то специальном его значении, исходя из смысла положений ст. 31 Венской конвенции о праве международных договоров, данное понятие используется в таможенном праве в привычном для цивилистики [26, Особое мнение судьи Суда ЕАЭС Д.Г.Колоса]. А, значит, как подсказывает формальная логика, не подразумевает безусловной обязанности декларанта вернуть брокеру уплаченные им солидарно таможенные платежи без учета исполнения последним договорных обязательств.

У таможенного представителя отсутствует интерес в перемещении товара, обязательства, нацеленные на обеспечение достоверности декларирования груза, распределяются между брокером и декларантом в договоре, в связи с чем, ряд авторов полагает, что на таможенного представителя и «не должно возлагаться бремя связанных с таможенной очисткой платежей» [10]. Заметим, оно традиционно и не возлагается (кроме случая исполнения брокером солидарной обязанности согласно [1, пп. 4 п. 1 ст. 405], и

\footnotetext{
* Примечание: аналогичная норма имелась и в Таможенном кодексе Таможенного союза в пункте 1 статьи 16.
} 
в обычной практике декларант обеспечивает таможенного представителя надлежащей суммой денежных средств для уплаты таможенных платежей (если по условиям договора последний уплачивает причитающиеся суммы названных платежей; на такую возможность указывает часть 5 ст. 346 Закона о таможенном регулировании).

Однако, как отмечено выше, распределение обязательств в договоре между таможенным представителем и декларантом не свидетельствует об отсутствии у таможни права требовать солидарного исполнения публично-правовой обязанности уплачивать таможенные платежи, причем последние если и взыскиваются с брокеpa, то за счет денежного залога - с суммы обеспечения, наличие которой является неотъемлемым условием включения в реестр таможенных представителей.

Наличие солидарной обязанности не означает автоматического признания ее в качестве меры гражданско-правовой ответственности, не исключает защиту прав добросовестной стороны в договорных отношениях и ее законных интересов. Названная ответственность наступает исключительно при наличии причинноследственной связи между нарушением одной из сторон своих обязательств и возникшими убытками в размере таких убытков, на что справедливо указывают органы правосудия [21, п. 5; 25]. И если, например, в договоре отсутствует обязательство таможенного представителя определять классификационный код ЕТН ВЭД, потребовать возмещения убытков, возникших в результате уплаты недоимки за недостоверно задекларированный спорный груз, декларант уже не вправе [17]. В случае надлежащего и добросовестного исполнения обязательств таможенным брокером, то есть при отсутствии в его действиях вины, нет и оснований для ответственности перед представляемым лицом [13].

Итак, поскольку нормативное регулирование вопросов гражданско-правовой ответственности находится за рамками таможенного права и вне сферы деятельности Евразийской экономической комиссии, Апелляционная палата Суда ЕАЭС справедливо признала бездействие Комиссии правомерным.

Толкование солидарной обязанности по уплате таможенных платежей как возникающей «из закона» в предлагаемом Коллегией Суда значении, на мой взгляд, неизбежно при- вело бы к нарушению прав заинтересованных в качественной и профессиональной помощи лиц в сложном деле достоверного декларирования. Услуги брокера для декларанта превратятся в своеобразную «русскую рулетку»: заказчик оплачивает указанную в договоре услугу, брокер декларирует товар недостоверно, а образовавшаяся недоимка по таможенным платежам в любом случае возмещается заказчиком. Именно при таком подходе институт таможенного представителя утратит свою ценность.

В-третьих, как указала Коллегия Суда ЕАЭС, договор между таможенным представителем и декларантом не может регулировать вопросы их ответственности за неисполнение обязанности по уплате таможенных платежей. Напомним, однако, что юридическая ответственность (как гражданско-правовая за неисполнение договорных обязательств, так и административная и уголовная за нарушение таможенных правил) не установлена и международным договором - положениями ТК ЕАЭС (или в его развитие - национальным таможенным законодательством). Это сфера действия законодательства государствчленов Союза. Спор в настоящем деле возник ввиду принудительного взыскания таможней недоимки, порядок которой частично урегулирован Кодексом и в большей степени - законами о таможенном регулировании стран Союза. Меры по принудительному взысканию мерами юридической ответственности не являются. И даже если предположить, что в будущем юридическая ответственность за нарушение таможенных правил будет установлена в праве Союза (международным договором), сути дела это не изменит: исполнение публично-правовой обязанности декларантом в любом случае напрямую зависит от качества оказанных брокером услуг, перечень которых вытекает из договора. Публичная солидарная обязанность по уплате таможенных платежей брокера и декларанта своеобразный дополнительный инструмент для усиления «эффективности... принудительного взыскания таможенных платежей» [26, Особое мнение судьи Суда ЕАЭС Д.Г.Колоса со ссылкой на решения Суда ЕС - 30, 31]. Однако же, правоотношение по ее исполнению в силу такой ее зависимости от надлежащего исполнения обязательств брокера, полностью положениями международного договора, тем не менее, не урегулировано. Иная точка зрения высказывается судьей Суда ЕАЭС Т.Н.Нешатаевой [26]. 
Установление и оценка добросовестности сторон, обстоятельств неисполнения лицами своих договорных обязательств, повлекших убытки одного из них, в том числе ввиду привлечения к административной или уголовной ответственности, принудительного взыскания таможенных и иных подлежащих уплате обязательных платежей - задача органов правосудия стран Союза.

В ходе разрешения рассматриваемого спора арбитражные суды внимательно изучили договор между брокером-истцом и заказчикомдекларантом в целях установления перечня оказанных последнему услуг, в том числе ненадлежащего качества, повлекших недостоверное декларирование товара.

Как следует из содержания описательной части постановления Девятого арбитражного апелляционного суда от 01 октября 2019 г. [18], согласно договору, брокер обязан получить предварительное решение о классификации товара в соответствии с ТН ВЭД Таможенного союза. Из содержания этого и иных судебных актов по настоящему делу $[7,16]$ сложно понять, было ли получено такое предварительное решение, или нет. И была ли в этом на тот момент необходимость. Как следует из содержания приведенного судебного акта, брокер получил заключение эксперта, позволяющее определить функциональное предназначение товара и соответствующую ему классификационную позицию по ЕТН ВЭД. Таким образом, на первый взгляд, истец предоставил доказательства добросовестного поведения в целях исполнения публично-правовой обязанности и своего обязательства перед декларантом. И что мешало отстаивать свои интересы в споре о недоимке с таможенным органом? Исключительно желание вернуть утраченный статус таможенного представителя (восстановиться в реестре), страх растерять оставшихся клиентов. Именно это объясняет попытку брокера возместить свои расходы через признание их в судебном порядке убытками. В правоприменительной практике ранее высказывалось мнение о том, что таможенные платежи, подлежащие уплате, в понимании статьи 15 ГК РФ убытками не являются [20]. Здесь мы неизбежно сталкиваемся с вопросом определения убытков, который долгие годы остается дискуссионным. Полагаю, в рассматриваемом случае мы имеем дело с «положительным ущербом», сопряженном «с уменьшением наличного имущества» [2, С. 102] потерпевшей стороны, о чем косвенно свидетельствуют судебные решения по рассматриваемой категории споров. Но в таких случаях опять же следует установить причинно-следственную связь между неисполненной публично-правовой обязанностью в силу ненадлежащего исполнения обязательств и возникновением убытков у одной из сторон. Полагаем, брокеру надлежало доказать достоверность декларирования в споре с таможенным органом (при разрешении дела в порядке главы 24 АПК РФ). И тогда вопрос об убытках мог и не возникнуть. Решения по делам, вытекающим и административных и иных правоотношений (включая принятые по делам об административных правонарушениях) имеют преюдициальное значение при установлении вины той или иной стороны в неисполнении договорных обязательств. И, как следствие, могут послужить основанием для признания права на возмещение убытков.

В случае непризнания брокером требований таможенного органа, дело могло бы обернуться и в его пользу, поскольку суд принимает во внимание доводы подконтрольных фиску лиц, и, объективно оценив все доказательства, вправе сделать «вывод о верности классификации, произведенной декларантом, и об отсутствии в связи с этим у таможенного органа основания для принятия решения об иной классификации товара» [22, абз. 3 п. 21].

Итак, мнение заявителя о том, что положения союзного Таможенного кодекса не соблюдаются в правоприменительной практике Российской Федерации, не подтверждается содержанием судебных актов, вынесенных не в его пользу на территории нашего государства. К сожалению, эти обстоятельства дела Коллегией Суда ЕАЭС не были приняты во внимание.

Важность решения апелляционной инстанции Суда ЕАЭС по рассматриваемому делу бесспорна: оно поставило заслон нечистоплотным посредникам, желающим обогатиться за счет декларанта. Это решение также подтверждает правильность сложившегося в практике алгоритма признания права таможенного представителя, уплатившего таможенные платежи солидарно, на возврат таких сумм: сначала оспаривается решение таможни о классификации товара (или иное решение). Если оно признано незаконным, излишне уплаченные суммы подлежат возврату. Если решение таможни по вопросам таможенного обложения признается законным, вопрос 
о возврате солидарно уплаченных таможенных платежей может быть решен в деле о признании их в качестве убытков брокера лишь при наличии доказательств неисполнения декларантом договорных обязательств, повлекших указанные расходы представителя (например, заказчик представил исполнителю недостоверную информацию о товаре).

Стоит, однако заметить, что проблема отнюдь не так проста и ее решение не исчерпывается актами органов правосудия по рассматриваемому спору.

Изучив судебные решения о взыскании убытков с аналогичной рассматриваемому делу фабулой [12], либо возникших в случаях привлечения декларанта к административной ответственности за недостоверное декларирование [14], можно заключить: примеров негативной для таможенных представителей практики немало.

Ошибочное декларирование таможенным представителем кода ЕТН ВЭД при наличии достоверной информации о товаре, представленной декларантом [15],- типичная причина для возникновения споров такого рода.

Казалось бы, для избежания подобных ситуаций брокер предпринимает все необходимые меры: до включения в реестр страхует риск ненадлежащего исполнения обязательств и гарантирует уплату таможенных и иных, установленных Кодексом, платежей (причем на огромные суммы), пользуется сертифицированным программным обеспечением в целях заполнения и отправления деклараций на товар в центры электронного декларирования, применяет риск-ориентированный подход, привлекает экспертов в своей работе. Тем не менее, такая организация перманентно находится под угрозой применения принудительных мер.

Думаю, напряженность в немалой степени обусловлена нестабильностью норм таможенного обложения и его практики, что неизбежно влечет нарушение баланса частных и публичных интересов. Очевидно, что положения ТК ЕАЭС и Закона о таможенном регулировании нацелены именно на обеспечение принципа стабильности. Например, срок действия предварительного решения в России продлен до 5 лет. Декларант и брокер разумно ожидают, что при декларировании идентичного товара применим привычный в практике код, и это их ожидание обычно подтверждаются беспрепятственным выпуском то- вара. И даже «несмотря на то, что обязательность предварительных классификационных решений таможенного органа ограничена конкретными товарами, которые были ввезены получателем такого решения, иные участники внешнеэкономической деятельности могут руководствоваться ими, так как сами по себе предварительные решения являются официальным документом органа государственной власти, выражающим его позицию относительно классификации того или иного вида товаров (практики)». В этой связи, принятие решения ЕЭК о классификации, отличного от действовавшего несколько лет решения Комиссии [9] или ФТС России, не должно распространятся на случаи декларирования товаров до его принятия [23, п. 17; 22, п. 9; 8; 19]. Однако на деле декларанты и брокеры доходят до Верхового Суда РФ, добиваясь соблюдения названных исходных начал таможенного обложения - стабильности таможенных правил и недопустимости ретроактивного применения вновь принятых норм, ухудшающих правовой статус плательщика.

Представляется, что неукоснительное соблюдение названных принципов в части исполнения предварительных решений и складывающейся в этой связи практики, в том числе связанной с комплексной реализацией норм таможенного и гражданского права, изучение формируемых правовых позиций высших органов правосудия в государствах интеграционного образования - вопросы, которые находятся в поле зрения Евразийской экономической комиссии. Данное направление деятельности Комиссии является одним из проявлений ее базовой функции - обеспечения реализации международных договоров, входящих в право Союза [23, п. 4]. Не случайно в структуре ее правового департамента имеется отдел организации мониторинга и судебно-правовой работы. Поэтому вполне ожидаемый шаг - выработка на уровне Евразийского экономического союза единых подходов в правоприменении.

В этой связи, Комиссии надлежит на постоянной основе изучать причины исключения таможенных представителей из реестра, поскольку нередко они кроются в неверной классификации товара таможней, определяемого по итогам контроля после выпуска. Мониторинг поможет выявить спорные товарные позиции, по которым Комиссия вправе принимать предварительные решения, действующие на всей 
территории Союза. Наличие таковых поспособствует профилактике таможенных споров.

И последнее. В целях защиты интересов декларанта и повышения качества оказываемых ему услуг полагаю необходимым усилить контроль за профессиональной деятельностью сотрудников таможенных представителей: вернуть в ТК ЕАЭС (ст. 402) и Закон о таможенном регулировании (ст. 347) положения об обязательном наличии в штате таможенных представителей специалистов по таможенным операциям (с соответствующим профильным образованием) и выдаче им квалификационных аттестатов центральными таможенными ведомствами государств-членов Союза. Возможно также рассмотреть вопрос о повышении квалификации указанных специалистов под «крылом» Евразийской экономической комиссии, что позволит обеспечить унификацию не только применения, но и исполнения нормативных актов по вопросам таможенного дела на всей территории интеграционного образования.

\section{Библиографический список}

1. Договор о Таможенном кодексе Евразийского экономического союза (Подписан в г. Москве 11 апреля 2017 г., в ред. протокола от 29 мая 2019 г.) (приложение № 1 - Таможенный кодекс ЕАЭС) // Официальный сайт Евразийского экономического союза.- URL: http://www.eaeunion.org/, 12.04.2017 (дата обращения 21.07.2021).

2. Иоффе О. С. Обязательственное право. М.: Юрид, лит., 1975. 880 с.

3. Козырин А.Н. Правовое регулирование таможенно-тарифного механизма: Сравнительно-правовое исследование: Дисс. ... д-ра юрид. наук. М., 1994. 404 с.

4. Кулаков В.В. Обязательство и осложнение его структуры в гражданском праве России. М.: РАП; Волтерс Клувер. 2010. 256 с.

5. Мотуренко С. М. Правовое положение таможенных посредников: Дисс. ... канд. юрид. наук. М., 2005.169 с.

6. Новиков А. Б. Таможенное право. Общая часть (дискуссионные вопросы лекционного курса): Учеб. пособие. СПб.: ГИОРД, 2006. 138с.

7. Определение Верховного Суда РФ от 18 июня 2020 г. № 305-ЭС20-6180 по делу № А40-21930/2019.

8. Определение Судебной коллегии по экономическим спорам Верховного Суда РФ от 01 февраля 2018 г. № 305-КГ17-16017 по делу № А40-174421/2016.

9. Определение Судебной коллегии по экономическим спорам Верховного Суда РФ от 19 июня 2020 г. № $303-$ эС20-816 по делу № А51-24425/2018.

10. Покачалова Е.В., Бакаева О.Ю., Разгильдиева М.Б., Садчиков М.Н. Институт таможенного представителя: проблемы правоприменительной практики в контексте уплаты фискальных платежей публичного характера (часть 1) // Финансовое право. 2021. № 6. С. 31-36 (Доступ из СПС «КонсультантПлюс»).

11. Попова М.Е. Гражданско-правовые аспекты современного таможенного законодательства: Дисс. ... канд. юрид. наук. М., 1999. 191 с.

12. Постановление Арбитражного суда Дальневосточного округа от 01 февраля 2021 г. № Ф03-5932/2020 по делу № А51-16164/2019.

13. Постановление Арбитражного суда Московского округа от 11 апреля 2016 г. № Ф05-3146/2016 по делу № A40-142726/2014 (Определение Верховного суда РФ от 11 августа 2016 г. № 305-ЭС16-9097 отказано в передаче дела № А40-142726/2014 в Судебную коллегию по экономическим спорам Верховного Суда РФ для пересмотра данного постановления в порядке кассационного производства).

14. Постановление Арбитражного суда Московского округа от 02 февраля 2018 г. № Ф05-11837/2018 по делу № A40-185255/17.

15. Постановление Арбитражного суда Московского округа от 24 декабря 2019 г. № Ф05-20851/2019 по делу № A40-312735/2018.

16. Постановление Арбитражного суда Московского округа от 24 января 2020 г. № Ф05-23878/2019 по делу № А40-21930/2019.

17. Постановление Арбитражного суда Московского округа от 14 января 2021 г. № Ф05-22934/2020 по делу № A41-87065/2019.

18. Постановление Девятого арбитражного апелляционного суда от 01 октября 2019 г. № 09АП-42988/2019 по делу № A40-21930/2019.

19. Постановление Девятого арбитражного апелляционного суда от 15 февраля 2021 г. № 09АП-65222/2020 по делу № A40-43681/2020. 
20. Постановление ФАС Северо-Кавказского округа от 29 июля 2004 г. № Ф08-3060/2004.

21. Постановление Пленума Верховного Суда Российской Федерации от 24 марта 2016 г. № 7 «О применении судами некоторых положений Гражданского кодекса Российской Федерации об ответственности за нарушение обязательств».

22. Постановление Пленума Верховного Суда РФ от 26 ноября 2019 г. № 49 «О некоторых вопросах, возникающих в судебной практике в связи с вступлением в силу Таможенного кодекса Евразийского экономического союза» // Бюллетень Верховного Суда РФ. 2020. № 1.

23. Приложение № 1 к Договору о Евразийском экономическом союзе от 29 мая 2014 г. «Положение о Евразийской экономической комиссии» (в ред. договоров от 10 октября 2014 г., 23 декабря 2014 г. и протоколов от 8 мая 2015 г., 15 марта 2018 г., 01 октября 2019 г.) // СПС «КонсультантПлюс».

24. Решение Апелляционной палаты Суда ЕАЭС от 09 июня 2021 г. «Об отмене Решения Суда Евразийского экономического союза от 27.04.2021 № CE-1-2/5-21 КС и признании бездействия ЕЭК соответствующим Договору о ЕАЭС и не нарушающим права и законные интересы хозяйствующего субъекта в сфере предпринимательской и иной экономической деятельности».

25. Решение Арбитражного суда г. Москвы от 29 мая 2019 г. по делу № А40-21930/2019-19-195 (со ссылкой на п. 5 постановления Пленума Верховного Суда Российской Федерации от 24 марта 2016 г. № 7 «О применении судами некоторых положений Гражданского кодекса Российской Федерации об ответственности за нарушение обязательств»).

26. Решение Коллегии Суда ЕАЭС от 27 апреля 2021 г. № CE-1-2/5-21 КС «О признании бездействия Евразийской экономической комиссии союза и нарушающими права и законные интересы хозяйствующего субъекта в сфере предпринимательской деятельности и иной экономической деятельности».

27. Федеральный закон от 03 августа 2018 г. № 289-Ф3 «О таможенном регулировании в Российской Федерации и о внесении изменений в отдельные законодательные акты Российской Федерации» (с изм. и доп., включая от 02 июля 2021 г.) // СЗ РФ. 2018. № 32 (часть І). Ст. 5082; 2021. № 27 (Ч. І). Ст. 5130.

28. Халипов С.В. Таможенный представитель: ответы на экзаменационные вопросы для специалистов по таможенным операциям. 16-е изд-е, перераб. М.: ИД «Юриспруденция», 2018. 288 с.

29. Шерстобитов В.Ю. Совершенствование административно-правового регулирования деятельности таможенных представителей: Дисс. ... канд. юрид. наук. Люберцы, 2014. 177 с.

30. Judgment of the Court (Fourth Chamber) of 17 February 2011. Marc Berel and Others v Administration des douanes de Rouen, Receveur principal des douanes du Havre, Administration des douanes du Havre. Case C-78/9 / OJ C103/9, 2.4.2011.- URL: https://op.europa.eu/en/publication-detail/-/publication/d28e513e-6d10-4336-b898430ff1be1f28/language-en (дата обращения: 29.07.2021).

31. Judgment of the Court (Eighth Chamber) of 18 May 2017. 'Latvijas Dzelzceľ̦s' VAS v Valsts ienemumu dienests. Case C-154/16 / OJ C239/15, 24.7.2017. https://eur-lex.europa.eu/legal-content/EN/TXT/PDF/?uri=CELEX:62016C J0154\&rid=2 (дата обращения: 29.07.2021). 